\title{
Correlation analysis of stem hardness traits with fiber and yield-related traits in core collections of Gossypium hirsutum
}

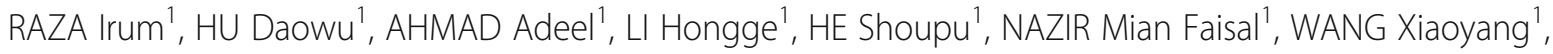 \\ JIA Yinhua', PAN Zhaoe ${ }^{1}$, ZHANG Peng ${ }^{1}$, YASIR Muhammad ${ }^{1}$, IQBAL Muhammad Shahid', GENG Xiaoli', \\ WANG Liru', PANG Baoyin ${ }^{1}$ and DU Xiongming ${ }^{1,2^{*}}$
}

\begin{abstract}
Background: Stem hardness is one of the major influencing factors for plant architecture in upland cotton (Gossypium hirsutum L.). Evaluating hardness phenotypic traits is very important for the selection of elite lines for resistance to lodging in Gossypium hirsutum L. Cotton breeders are interested in using diverse genotypes to enhance fiber quality and high-yield. Few pieces of research for hardness and its relationship with fiber quality and yield were found. This study was designed to find the relationship of stem hardness traits with fiber quality and yield contributing traits of upland cotton.

Results: Experiments were carried out to measure the bending, acupuncture, and compression properties of the stem from a collection of upland cotton genotypes, comprising 237 accessions. The results showed that the genotypic difference in stem hardness was highly significant among the genotypes, and the stem hardness traits ( $\mathrm{BL}, \mathrm{BU}, \mathrm{AL}, \mathrm{AU}, \mathrm{CL}$, and $\mathrm{CU}$ ) have a positive association with fiber quality traits and yield-related traits. Statistical analyses of the results showed that in descriptive statistics result bending (BL, BU) has a maximum coefficient of variance, but fiber length and fiber strength have less coefficient of variance among the genotypes. Principal component analysis (PCA) trimmed quantitative characters into nine principal components. The first nine principal components (PC) with Eigenvalues $>1$ explained 86\% of the variation among 237 accessions of cotton. Both 2017 and 2018, PCA results indicated that BL, BU, FL, FE, and $L I$ contributed to their variability in PC1, and $B U, A U, C U, F D$, $L P$, and FWPB have shown their variability in PC2.
\end{abstract}

Conclusion: We describe here the systematic study of the mechanism involved in the regulation of enhancing fiber quality and yield by stem bending strength, acupuncture, and compression properties of G. hirsutum.

Keywords: Bending, Compression, Acupuncture, Principle component analysis, Stem hardness

\footnotetext{
*Correspondence: dxm630723@163.com; dujeffrey8848@hotmail.com

'State Key Laboratory of Cotton Biology, Institute of Cotton Research, Chinese Academy of Agricultural Sciences, Anyang 455000, Henan, China

${ }^{2}$ School of Agricultural Sciences, Zhengzhou University, Zhengzhou 450001, China
}

(c) The Author(s). 2021 Open Access This article is licensed under a Creative Commons Attribution 4.0 International License, which permits use, sharing, adaptation, distribution and reproduction in any medium or format, as long as you give appropriate credit to the original author(s) and the source, provide a link to the Creative Commons licence, and indicate if changes were made. The images or other third party material in this article are included in the article's Creative Commons licence, unless indicated otherwise in a credit line to the material. If material is not included in the article's Creative Commons licence and your intended use is not permitted by statutory regulation or exceeds the permitted use, you will need to obtain permission directly from the copyright holder. To view a copy of this licence, visit http://creativecommons.org/licenses/by/4.0/. 


\section{Introduction}

Cotton is one of the most important cash crops and major fiber crops in the world. The contribution of cotton to the total fiber used worldwide is about 35\% (Zhang et al. 2014). Upland cotton (Gossypium hirsutum L.) is the largest cultivated species of cotton, accounting for more than $90 \%$ of the world cotton cultivated areas, which reflects widespread adaptability and high yield production characteristics (Wendel 1989; Chen et al. 2007). Gossypium hirsutum L. is allotetraploid $(2 \mathrm{n}=4 \mathrm{x}=52)$, and is composed of two ancestral genomes that are designated as At from Gossypium arboreum and Dt from Gossypium raimondii (Al-Ghazi et al. 2009). Due to the long-term natural selection and artificial breeding, several cotton germplasm resources for sustainable genetic improvement have been created under varied climatic and cultivating conditions. In the National Gene Bank for Cotton, China, 7712 G. hirsutum accessions have been assessed. All these accessions were collected from many cotton-producing countries around the world since 1865 when the United States introduced upland cotton (Dai et al. 2016). To efficiently use these resources, various efforts have been made to investigate and evaluate cotton diversity (Fang et al. 2017b; Huang et al. 2017; Sun et al. 2017; Wang et al. 2017; Ma et al. 2018).

The yield and quality of the products are the most important factors for all crops (Fang et al. 2017a). Stem hardness is a basic characteristic in the plant architecture of cotton and supports a large load under adverse conditions, which is not well studied. Stem hardness may have a relationship with yield and fiber quality. The physical characteristics contributing to the strength of the stem are the bending force, puncture force, and compression force. The stem bending force is the force at which the trunk bends or breaks under a particular load. The basal portion of the culm internode plays a crucial role in ensuring the plant to remain upright (Peng et al. 2014). The greater carbohydrate accumulation in the base stem could increase the force need to bend the stem (Ishimaru et al. 2008). Stem thickness is a biological indicator of green or dry biomass. The strength (force, stress) and energy requirements are the compressive properties. Therefore, the selection of genotypes with increased stem strength is a useful field indicator (Beeck et al. 2006). Compression properties of stem depend on species, variety, stalk structure, stalk diameter, maturity, moisture, and cell structure (Persson 1987). A physical quantitative measurement may enhance selection effectiveness and boost genetic gain, such as penetrometer sorghum measurement (Peddersen and Toy 1999). Therefore, a greater understanding of these parameters provides a theoretical basis to enhance the physical strength of the stem and basal part of the culm internode, to obtain higher yield and good fiber quality of cotton.

Amorphous fibrils, lignin and pectin in the cell wall are also known to enhance the strength and hardness of the stem (Mohsenin 1986). Lignin or cellulose generally determines physical strength, as low content of lignin or cellulose causes a brittle culm (Tanaka et al. 2003). In wheat the mechanical strength of the stem is provided by cellulose and lignin to the lodging resistance in plants (Cai et al. 2019). The selection of elevated stalk strength and resistance to the corn borer (genus: Ostrinia, species: O. nubilalis) increases the elements of cell walls in the breeding program (Li et al. 2016). Cotton has a high biomass output and a high cellulose and lignin proportion. In mature cotton fiber, the secondary cell wall (SCW) includes over $90 \%$ cellulose and it differs from all other known species of plant by having the only known source of cellulose in such high concentration and purity. By contrast, typical SCWs contain $40 \% \sim 50 \%$ cellulose in dicotyledonous stem xylem (Huang et al. 2016). An exhaustive study of stem hardness in cotton might, therefore, allow the cell wall to be modified to improve fiber quality and quantity because plant cell wall has a close association with mechanical and biochemical strength of stem parameters.

Principal component analysis (PCA) has been used extensively in the plant sciences for variable reduction and genotype grouping. This is the most prevalent statistical multivariate method used in environmental studies (Tahri et al. 2005; Yongming et al. 2006). PCA is commonly used in the analysis of the relationships between observed variables and in the extraction of a small number of autonomous factors (major component) (Tokalıglu and Kartal 2006). It commences with the correlation matrix and describes the dispersion of the original variables, extracts eigenvalues and eigenvectors (Astel et al. 2008). The eigenvector is a list of coefficients that multiply the original correlated variants to obtain new uncorrelated (orthogonal) principal components that are linearly weighted combinations of the original variables. The number of correlated variables can be reduced to a smaller set of orthogonal factors, which allows the interpretation of a specified multidimensional system by showing correlations between the original variables. The analysis of the correlations also reflects a related response of a given character and provides a good index for predicting the corresponding change in one character to the extent of the proportional change in the other. PCA was used by Kamara et al. (2003) to identify maize (Zea mays L.) traits which accounted for the majority of variance in the data. Granati et al. (2013) have used PCA to investigate the relationship between Lathyrus accessions. Žáková and Benková (2006) identified the traits of 106 Slovak barley accessions as the primary sources of 
variations in genetic diversity. PCA and cluster analysis were used by Cartea et al. (2002), Salihu et al. (2006), respectively, to group kale populations and genotypes of winter wheat. The current study examined the multivariate data analysis of agronomic and quality characteristics of a global collection of 237 genotypes.

Some studies have been conducted on stem strength behaviors of different plants; however, for stem hardness characteristics of cotton stalk, no data has been reported. The present research, therefore, seeks to establish a relationship between stem hardness and yield characteristics and quality characteristics in Gossypium hirsutum. However, the yield is a complicated, multi-component controlled character. Stem hardness components are less sensitive than yield per se to the environmental changes and are therefore comparatively more likely to improve with selection. Once the nature and extent of relations among these characteristics and yield are understood, the effectiveness of choice in the segregated generation will be improved. Therefore, the present research was carried out to assess the PCA and correlations of significant G. hirsutum characteristics.

\section{Materials \& methods}

\section{Cotton accessions}

From a set of 7362 G. hirsutum accessions, preserved at the China National Gene Bank, Institute of Cotton Research, Chinese Academy of Agriculture Sciences, Anyang, Henan, 237 cotton genotypes were selected. These accessions have various geographical origins including China, the United States, the former Soviet Union, Australia, Brazil, Pakistan, Mexico, Chad, Uganda, and Sudan, which are most of the world's largest cottongrowing areas.

\section{Planting and phenotyping}

Phenotyping of stem hardness-related features was recorded during the normal cotton-growing season (mid-April to late-October) at Institute of Cotton Research, Anyang, Henan, China (the Yellow River area) for 2 years, i.e., 2017 and 2018. Coordinates of the location are $\mathrm{E} 114.07^{\circ}$ and $\mathrm{N} 35.85^{\circ}$, longitude and latitude, respectively. All accessions (237) were planted in a randomized complete block design with three replicates in the experimental field. Each entry plot had a dimension of $7 \mathrm{~m} \times 3 \mathrm{~m}$, row-to-row and plantto-plant distance was $76 \mathrm{~cm}$ and $30 \mathrm{~cm}$, respectively. Field management practices were conducted according to the local management scheme. The scoring standards for phenotypic traits in both years were identical. Six stem hardness traits and 14 agronomic traits were characterized.

\section{Sample preparation for stem hardness traits}

The stems were cut and separated from the branches after harvesting. Stem samples were air-dried for 2 months in the lab. At the time of hardness testing, the air-dried cotton stem had low humidity content. The stem was equally divided into two parts for the preparation of test samples: upper and lower (Additional file 2: Figure S1a).

\section{Stem hardness traits}

For each replicate, three plants were selected to test the hardness of the stem. These characteristics were the breaking force of the upper part (BU), the breaking point of the lower part (BL), the compression force of the upper and lower part (CU and $\mathrm{CL}$ ), and the acupuncture force of the upper and lower part (AU and $\mathrm{AL}$ ). The YYD-1 SS testing system (TOP Instrument Co., Zhejiang, China) was used to measure all hardness characteristics of a $15 \mathrm{~cm}$ segment from the lower, and upper part of the stem (Additional file 2: Fig. S2b). The tester was set perpendicular to the culm at the middle, under gradual loading, and the breaking force was measured when the culm was pushed to breaking point. The maximum force in Mega Newtons needed to break, puncture \& compress the center of the two segments of the stem (upper and lower) was recorded.

\section{Agronomic traits}

Days to first flower opening, FD (days), were calculated from the date of sowing to the day when first flowers bloomed on $50 \%$ of the plants in each plot. Plant height $(\mathrm{PH})$ is recorded from the base of the plant above ground to the tip of the plant. Ten consecutive plants were selected for plant height in each plot. From each accession, 30 naturally opened bolls were harvested randomly to calculate boll weight (BW) and to gin the fiber. The seed index (SI) was calculated after counting and weighing 100 cotton seeds. Fiber samples were separately weighed to calculate the lint percentage (LP) and fiber weight per boll (FWPB). The lint index (LI) was calculated based on SI and LP data.

$$
\text { Lintindex }=\frac{\text { Seedindex } \times \text { Lintpercentage }}{1-\text { Lintpercentage }}
$$

Fiber samples were examined in the Cotton Quality Test Center in Anhui, China for fiber-quality characteristics using a high-volume instrument (HFT9000). Data on the fiber length $(\mathrm{FL}, \mathrm{mm})$, fiber strength $\left(\mathrm{cN} \cdot \mathrm{tex}^{-1}\right)$, micronaire value (Mic, $\mu \mathrm{g} \cdot \mathrm{inch}^{-1}$ ), elongation percentage (EP, $\%$ ), length uniformity (LU, \%), spinning consistency index $(\mathrm{SCI})$ were recorded. The average of the three replicates in the same year is defined to be phenotypic information per accession. 


\section{Statistical analysis}

For the evaluation of phenotypic traits statistics, Minitab 18 and $\mathrm{R}$ were used. The primary impacts of the experimental variables and their relationships were analyzed by the analysis of variances (ANOVA). The significance level for ANOVA was set at $P \leq 0.05$. R software (package "corrplot") was used for calculating and plotting correlation. The principal component analysis was performed using Minitab 18.

\section{Results}

\section{Stem hardness variations among the genotypes}

The ANOVA results were given in Table 1 showing that genotypic differences in stem hardness were highly significant for traits like bending (BL and BU), and compression CU. Basic descriptive statistics (mean, standard deviation, minimum, maximum and coefficient of variance) of all the genotypes for morphological, yield and fiber traits were studied (Additional file 1: Table S1). It was observed in year 2018 data that maximum coefficient of variance $(26.67 \%$ \& $20.40 \%)$ was recorded in bending (BU \& BL), respectively, which mean and SD was $(0.08 \& 0.19,0.02 \& 0.04)$ followed by acupuncture upper and lower $(17.81 \%$ \& $15.76 \%)$ compression upper and lower (14.96\% \& $13.45 \%)$, seed index $(14 \%)$ and fiber length (14\%) with a mean and SD of $0.07,0.08,0.54$, $0.82,12.30 \& 30.39,0.01,0.01,0.08,0.11,1.43 \& 1.82$, respectively. The traits like fiber elongation (1.47) and fiber strength (3.43) have a comparably less coefficient of variance among the genotypes. In 2017 data bending (BU \& BL) have shown a maximum coefficient of variance similar to the 2018 result and also observed maximum coefficient of variance of compression upper (26.67\%). As similar to 2018 results it was also observed that fiber strength and fiber elongation have less coefficient of variance in 2017 data. All traits showed a similar trend of results in both years.

The results (Additional file 1: Table S2) showed the variation among different varieties. Based on the bending trait values all 237 accessions of cotton were differentiated into two groups, higher stem hardness (HSH), because those varieties that have the higher value of bending trait, and lower stem hardness (LSH), because of their lower values of bending traits. In Table S2, only six HSH genotypes and six LSH genotypes are mentioned in detail.

\section{Principal component analysis}

Principal component analysis was performed to only the principal component (PCs) with an eigenvalue higher than 1 according to the Kaiser (1960) criterion. Thus in the 2018 data PC1, PC2, PC3, PC4, PC5 and PC6 (Table 2) were selected as they represented 23\%, 14\%, $12 \%, 8 \%, 8 \%$, and $6 \%$ of progeny variation, respectively, and accounted for $73 \%$ of the overall diversity. If added PC7, PC8 and PC9, variances represented a cumulative percentage of $78 \%, 82 \%$ and $86 \%$, respectively. Table 2 summarizes the PCs and the eigenvectors, which were estimated on the average of 20 variables. All the 20 traits contributed to the total variation in $\mathrm{PC} 1$, but fiber length (FL), uniformity percentage (UP), fiber elongation (FE), lint index (LI), bending lower (BL), and bending upper (BU) have contributed more. PC1 is a weighted average of these characters indicating that fiber quality traits have significant importance for this component. While in PC2, all variables are significantly contributing, but the main contributors were bending upper (BU), acupuncture upper (AU), compression upper (CU), days to flowering (FD), lint percentage (LP) and fiber weight per boll (FEPB). So yield traits have more contribution in PC2. For PC3, bending lower (BL), compression lower $(\mathrm{CL})$, compression upper $(\mathrm{CU})$, bending upper $(\mathrm{BU})$, maturity $(\mathrm{M})$ and spinning consistency index $(\mathrm{SCI})$ is the leading important traits, while multiple traits contributed to the other PCs in varying proportions. The 2017 data are also given in Table 2.

\section{Stem hardness correlation with fiber quality traits}

The result of the 2018 correlation of stem hardness indicated that bending lower (BL) has a positive association with fiber length, micronaire value, uniformity percentage, fiber elongation, spinning consistency index, and days to flowering (Fig. 1). Bending upper (BU) has a positive correlation with FL, UP, SCI, and FD. Compression lower (CL) has a positive association with $\mathrm{FL}, \mathrm{M}, \mathrm{SCI}$, and $\mathrm{FD}$, while compression upper (CU) has a positive correlation with LU, SCI, and FD. Same result was found in the Additional file 2: Fig. S2, that the correlation of stem hardness traits bending (BL \& BU) have a positive association with UP, FL and FD. Compression (CU \& CL) showed a positive correlation with FD. In 2017 data, most of the traits showed the same trend as in 2018.

\section{Stem hardness correlation with yield-related traits and morphological traits}

In Fig. 2, the 2018 correlation result showed that bending lower (BL) have highly positively associated with $\mathrm{PH}$, GP, LP, and FWPB, while bending upper (BU) have a positive association with $\mathrm{PH}, \mathrm{GP}$, and LI. Acupuncture lower (AL) showed a positive correlation with PH. Compression (CL and $\mathrm{CU}$ ) has a positive correlation with $\mathrm{PH}, \mathrm{GP}, \mathrm{BW}$, and LI. We also found that BL, BU, CL and $\mathrm{CU}$ have a positive association with $\mathrm{PH}$ and GP (Additional file 2: Fig. S3). AU has a negative association with PH and a positive association with GP. 2017 data show the same trend as 2018 . 
Table 1 ANOVA for 20 traits in 2017 and 2018

\begin{tabular}{|c|c|c|c|c|c|c|c|c|c|}
\hline \multirow[t]{2}{*}{ Trait } & \multicolumn{2}{|c|}{ Sum of square } & \multicolumn{2}{|c|}{ Mean square } & \multicolumn{2}{|l|}{$F$ Value } & \multicolumn{2}{|c|}{ Significant } & \multirow[t]{2}{*}{$\begin{array}{l}R^{2} \\
\text { (adj) }\end{array}$} \\
\hline & G & $Y$ & G & $Y$ & G & $\mathrm{Y}$ & G & $\mathrm{Y}$ & \\
\hline $\mathrm{BL}$ & 1.05 & 0.30 & 0.004 & 0.30 & 1.49 & 102.80 & $* *$ & $* * *$ & 0.31 \\
\hline $\mathrm{AL}$ & 0.05 & 0.09 & 0.0002 & 0.09 & 0.88 & 341.10 & ns & $* * *$ & 0.39 \\
\hline $\mathrm{CL}$ & 2.78 & 3.39 & 0.01 & 3.39 & 1.19 & 343.16 & ns & $* * *$ & 0.45 \\
\hline BU & 0.19 & 0.03 & 0.001 & 0.03 & 1.60 & 60.21 & $* * *$ & $* * *$ & 0.29 \\
\hline $\mathrm{AU}$ & 0.02 & 0.002 & 0.0001 & 0.002 & 1.13 & 14.94 & ns & $* * *$ & 0.08 \\
\hline $\mathrm{CU}$ & 3.26 & 0.08 & 0.01 & 0.08 & 1.24 & 7.33 & * & $* *$ & 0.11 \\
\hline $\mathrm{PH}$ & 307.00 & 184.80 & 130.32 & 184.84 & 2.92 & 4.14 & $* * *$ & * & 0.49 \\
\hline BW & 128.80 & 294.80 & 0.55 & 294.75 & 1.02 & 551.00 & ns & $* * *$ & 0.53 \\
\hline GP & 489.00 & 5647.00 & 207.22 & 5646.00 & 3.30 & 89.85 & $* * *$ & $* * *$ & 0.57 \\
\hline LP & 8163.10 & 110.10 & 34.58 & 110.05 & 8.54 & 27.17 & $* * *$ & $* * *$ & 0.79 \\
\hline LI & 485.55 & 208.75 & 2.06 & 208.75 & 7.57 & 768.48 & $* * *$ & $* * *$ & 0.83 \\
\hline FWPB & 43.97 & 49.23 & 0.18 & 49.23 & 2.09 & 552.30 & $* * *$ & $* * *$ & 0.63 \\
\hline SI & 801.82 & 328.83 & 3.39 & 328.83 & 9.40 & 910.14 & $* * *$ & $* * *$ & 0.85 \\
\hline FS & 1221.70 & 68.37 & 5.18 & 68.37 & 0.86 & 11.36 & ns & $* *$ & 0.00 \\
\hline $\mathrm{FL}$ & 1339.10 & 671.90 & 5.67 & 671.89 & 7.14 & 845.55 & $* * *$ & $* * *$ & 0.82 \\
\hline UP & 691.97 & 11.96 & 2.93 & 11.96 & 2.57 & 10.47 & $* * *$ & $* *$ & 0.44 \\
\hline $\mathrm{SCl}$ & 105.00 & 0.10 & 447.86 & 0.10 & 3477.25 & 0.80 & $* * *$ & ns & 0.99 \\
\hline FD & 101.00 & 1975.00 & 43.10 & 1975.00 & 2.04 & 935.48 & $* * *$ & $* * *$ & 0.71 \\
\hline $\mathrm{FE}$ & 31.50 & 0.0001 & 0.13 & 0.0001 & 3.33 & 0.00 & $* * *$ & ns & 0.53 \\
\hline $\mathrm{Ml}$ & 86.54 & 0.04 & 0.36 & 0.04 & 4.84 & 0.59 & $* * *$ & ns & 0.65 \\
\hline
\end{tabular}

G genotype, $Y$ year, $n s$ non-significant, ${ }^{*},{ }^{* *}$ and ${ }^{* * *}$ : significant at $P<0.05, P<0.01$, and $P<0.001$, respectively. $B L$ bending lower, $A L$ acupuncture lower, $C L$ compression lower, $B U$ bending upper, $A U$ acpuncture upper, $C U$ compression upper, $P H$ plant height, $B W$ boll weight, $G P$ growth period, $L P$ lint percentage, $L /$ lint index, FWPB flowering weight per boll, $S /$ seed index, FS fiber strength, FL fiber length, UP uniformity percentage, $S C l$ spinning consistency index, FD days to flowering, $F E$ fibre elongation, $M I$ micronaire

\section{Discussion}

In the last decade, there has been great progress in developing new cotton genotypes for better fiber quality and higher yield. The stem-associated characteristics such as bending, acupuncture, and compression may be used to determine the yield and quality of the fiber. One reasonable factor influencing crop quality and yield is plant height (Tang et al. 2007). The fiber quality parameters on which textile processing and the quality of the item rely are fiber strength and length because those attributes receive premium pricing (Hussain et al. 2010).

Our breeding program goal for G. hirsutum was the identification of to identify high-yield genotypes, and some agronomic features that are easily evaluated and linked with these characteristics that could be used as markers (Chen et al. 2007, 2014). In this study, we observed that the bending, compression, and acupuncture related to stem hardness have a positive and substantial correlation with the fiber length, spinning consistency, and flowering times. Pettigrew (2001 \& 2008) reported that an increase in light and temperature also increased the strength, the difference was however not enough to cause a yield penalty. Our findings showed a positive association of length uniformity, micronaire values with stem hardness characteristics. Fiber fineness was positively associated with fiber length and fiber strength by Killi et al. (2005). There was a negative association of fiber fineness with a fiber strength and fineness with fiber strength and fiber uniformity ratio. The fiber strength showed a positive correlation with fiber uniformity. Mature cotton fibers are approximately $95 \%$ cellulose with other polysaccharides such as arabinose, galactose, and xylose (Meinert and Delmer 1977) and pectin (Meinert and Delmer 1977; Wang et al. 2010). These are important for determining may enhance fiber strength by joining cellulose fibrils. A direct correlation between cellulose molecular weight and fiber strength was reported by Timpa and Ramey (1994). Though there may be an extra metabolic cost of these polysaccharides, is higher (Amthor 2010), a higher metabolic cost, unless transport of complex polysaccharides was an issue it is in such a small proportion to the cellulose that it, seems unlikely to be a yield drain for such small fractions of 
Table 2 Eigenvectors and eigen analysis of the correlation matrix for the nine principal components traits associated with stem hardness performance in $G$. hirsutum accessions

\begin{tabular}{|c|c|c|c|c|c|c|c|c|c|c|}
\hline Traits & Years & PC1 & PC2 & PC3 & PC4 & PC5 & PC6 & PC7 & PC8 & PC9 \\
\hline \multirow[t]{2}{*}{$\overline{B L}$} & 2017 & 0.18 & 0.42 & 0.02 & -0.04 & -0.12 & -0.13 & 0.07 & -0.01 & 0.12 \\
\hline & 2018 & 0.26 & 0.09 & 0.38 & 0.05 & 0.00 & -0.15 & -0.08 & 0.13 & 0.01 \\
\hline \multirow[t]{2}{*}{$A L$} & 2017 & 0.04 & 0.16 & 0.17 & -0.23 & 0.47 & -0.40 & 0.04 & -0.1 & 0.48 \\
\hline & 2018 & 0.09 & 0.1 & 0.19 & -0.1 & -0.57 & 0.00 & -0.04 & -0.09 & -0.11 \\
\hline \multirow[t]{2}{*}{$\mathrm{CL}$} & 2017 & 0.11 & 0.28 & -0.05 & 0.00 & -0.4 & 0.00 & 0.13 & 0.16 & 0.37 \\
\hline & 2018 & 0.14 & 0.01 & 0.29 & 0.00 & 0.5 & -0.05 & 0.01 & -0.28 & 0.03 \\
\hline \multirow[t]{2}{*}{ BU } & 2017 & 0.19 & 0.40 & 0.05 & 0.00 & -0.19 & -0.13 & -0.02 & -0.13 & -0.21 \\
\hline & 2018 & 0.22 & 0.18 & 0.43 & 0.05 & -0.05 & -0.11 & 0.02 & 0.04 & 0.02 \\
\hline \multirow[t]{2}{*}{$A U$} & 2017 & 0.10 & 0.26 & 0.14 & -0.26 & 0.43 & -0.22 & -0.02 & 0.06 & -0.27 \\
\hline & 2018 & 0.06 & 0.13 & 0.15 & -0.13 & -0.53 & 0.02 & -0.06 & -0.40 & 0.15 \\
\hline \multirow[t]{2}{*}{ CU } & 2017 & 0.15 & 0.40 & 0.04 & -0.01 & -0.22 & -0.01 & 0.02 & 0.07 & -0.42 \\
\hline & 2018 & 0.17 & 0.17 & 0.39 & 0.01 & 0.28 & -0.08 & 0.00 & -0.18 & -0.06 \\
\hline \multirow[t]{2}{*}{ FS } & 2017 & -0.07 & 0.02 & 0.05 & -0.05 & -0.11 & -0.16 & -0.86 & 0.42 & 0.07 \\
\hline & 2018 & 0.32 & 0.09 & -0.29 & -0.09 & 0.02 & -0.12 & -0.05 & -0.05 & 0.21 \\
\hline \multirow[t]{2}{*}{$\mathrm{FL}$} & 2017 & 0.29 & -0.08 & 0.34 & 0.19 & 0.00 & -0.05 & 0.02 & 0.09 & 0.02 \\
\hline & 2018 & 0.37 & 0.06 & -0.19 & -0.06 & 0.03 & -0.04 & 0.12 & -0.08 & -0.01 \\
\hline \multirow[t]{2}{*}{ M } & 2017 & 0.14 & -0.02 & -0.51 & -0.25 & -0.02 & -0.07 & 0.11 & 0.36 & 0.13 \\
\hline & 2018 & 0.00 & -0.31 & 0.19 & -0.02 & 0.03 & 0.24 & -0.54 & 0.11 & 0.50 \\
\hline \multirow[t]{2}{*}{ UP } & 2017 & 0.31 & -0.08 & 0.18 & 0.19 & 0.12 & 0.03 & 0.06 & 0.16 & -0.02 \\
\hline & 2018 & 0.34 & -0.10 & -0.10 & -0.12 & 0.00 & 0.04 & -0.17 & 0.06 & 0.17 \\
\hline \multirow[t]{2}{*}{$\mathrm{FE}$} & 2017 & 0.24 & -0.07 & -0.01 & 0.15 & 0.05 & 0.07 & 0.27 & 0.54 & 0.19 \\
\hline & 2018 & 0.35 & -0.07 & -0.16 & -0.12 & 0.01 & 0.06 & -0.03 & 0.01 & 0.31 \\
\hline \multirow[t]{2}{*}{$\mathrm{SCl}$} & 2017 & 0.19 & -0.07 & 0.47 & 0.3 & -0.05 & 0.09 & -0.07 & -0.02 & 0.12 \\
\hline & 2018 & 0.35 & 0.13 & -0.27 & -0.12 & 0.01 & -0.17 & 0.19 & -0.02 & -0.03 \\
\hline \multirow[t]{2}{*}{ FD } & 2017 & 0.23 & 0.17 & -0.23 & 0.06 & 0.34 & 0.41 & -0.18 & -0.07 & 0.00 \\
\hline & 2018 & 0.08 & 0.31 & 0.01 & 0.37 & 0.00 & 0.433 & 0.19 & 0.15 & 0.20 \\
\hline \multirow[t]{2}{*}{$\mathrm{PH}$} & 2017 & 0.21 & 0.08 & -0.16 & 0.12 & -0.15 & 0.02 & -0.23 & -0.48 & 0.40 \\
\hline & 2018 & 0.16 & -0.17 & 0.18 & -0.14 & -0.11 & -0.16 & 0.14 & 0.75 & -0.11 \\
\hline \multirow[t]{2}{*}{ BW } & 2017 & 0.29 & -0.21 & 0.04 & -0.39 & -0.17 & 0.07 & -0.02 & -0.14 & 0.00 \\
\hline & 2018 & -0.04 & -0.08 & -0.07 & 0.54 & -0.10 & -0.52 & -0.03 & 0.00 & 0.22 \\
\hline \multirow[t]{2}{*}{ GP } & 2017 & 0.26 & 0.14 & -0.11 & -0.02 & 0.27 & 0.50 & -0.16 & 0.01 & -0.02 \\
\hline & 2018 & 0.09 & 0.36 & -0.06 & 0.37 & -0.05 & 0.36 & 0.04 & 0.16 & 0.05 \\
\hline \multirow[t]{2}{*}{ LP } & 2017 & 0.27 & -0.19 & -0.25 & 0.24 & 0.06 & -0.36 & -0.05 & -0.06 & -0.18 \\
\hline & 2018 & 0.22 & -0.42 & 0.06 & 0.08 & -0.05 & 0.3 & 0.17 & -0.13 & -0.23 \\
\hline \multirow[t]{2}{*}{ LI } & 2017 & 0.32 & -0.26 & -0.03 & -0.14 & -0.04 & -0.18 & -0.05 & -0.03 & -0.15 \\
\hline & 2018 & 0.29 & -0.23 & -0.03 & 0.20 & -0.02 & 0.23 & -0.27 & -0.07 & -0.5 \\
\hline \multirow[t]{2}{*}{ FWPB } & 2017 & 0.34 & -0.24 & -0.12 & -0.10 & -0.09 & -0.15 & -0.03 & -0.15 & -0.06 \\
\hline & 2018 & 0.13 & -0.37 & -0.01 & 0.48 & -0.11 & -0.18 & 0.10 & -0.12 & 0.04 \\
\hline \multirow[t]{2}{*}{ SI } & 2017 & 0.06 & -0.11 & 0.33 & -0.59 & -0.15 & 0.27 & 0.01 & 0.02 & 0.02 \\
\hline & 2018 & 0.06 & 0.32 & -0.16 & 0.13 & 0.03 & -0.16 & -0.65 & 0.10 & -0.32 \\
\hline \multirow[t]{2}{*}{ Eigenvalue } & 2017 & 5.42 & 3.07 & 1.78 & 1.55 & 1.36 & 1.23 & 0.99 & 0.87 & 0.75 \\
\hline & 2018 & 4.61 & 2.9 & 2.55 & 1.69 & 1.66 & 1.33 & 0.98 & 0.79 & 0.71 \\
\hline Proportion & 2017 & 0.27 & 0.15 & 0.08 & 0.07 & 0.06 & 0.06 & 0.05 & 0.04 & 0.03 \\
\hline
\end{tabular}


Table 2 Eigenvectors and eigen analysis of the correlation matrix for the nine principal components traits associated with stem hardness performance in G. hirsutum accessions (Continued)

\begin{tabular}{lllllllllll}
\hline Traits & Years & PC1 & PC2 & PC3 & PC4 & PC5 & PC6 & PC7 & PC8 & PC9 \\
\hline \multirow{4}{*}{ cumulative } & $\mathbf{2 0 1 8}$ & 0.23 & 0.14 & 0.12 & 0.08 & 0.08 & 0.06 & 0.04 & 0.04 & 0.03 \\
& $\mathbf{2 0 1 7}$ & 0.27 & 0.42 & 0.51 & 0.59 & 0.66 & 0.72 & 0.77 & 0.81 & 0.86 \\
& $\mathbf{2 0 1 8}$ & 0.23 & 0.37 & 0.50 & 0.58 & 0.67 & 0.73 & 0.78 & 0.82 & 0.86
\end{tabular}

$B L$ bending lower, $A L$ acupuncture lower, $C L$ compression lower, $B U$ bending upper, $A U$ acpuncture upper, $C U$ compression upper, $P H$ plant height, $B W$ boll weight, GP growth period, $L P$ lint percentage, $L I$ lint index, FWPB flowering weight per boll, $S /$ seed index, FS fiber strength, $F L$ fiber length, UP uniformity percentage, SCI spinning consistancy index

the fiber. There still exists the long-held fundamental reasons for a negative association or trade-off between yield or mass of fibers and quality components, such as strength, of individual fibers, and strength should be investigated further. Fiber diameter reduced from bottom to top, possibly because cell wall thickness decreased. Similarly, this can be explained by the fact that development in cell walls depends upon the accumulation of metabolism products (cellulose, hemicellulose, lignin, waxes, etc.) that rises with maturity (Ververis et al. 2003). The major requirement for increasing rice grain yield is to enhance the physical strength of the culm to enhance the breaking-type lodging resistance (Hirano et al. 2014). It has therefore been concluded that stem-related characteristics like bending stress have determined the morphology and the quality of the culm, such as cellulose, lignin, pectin inside the cell wall, which have a direct relationship to high yield and crop quality.

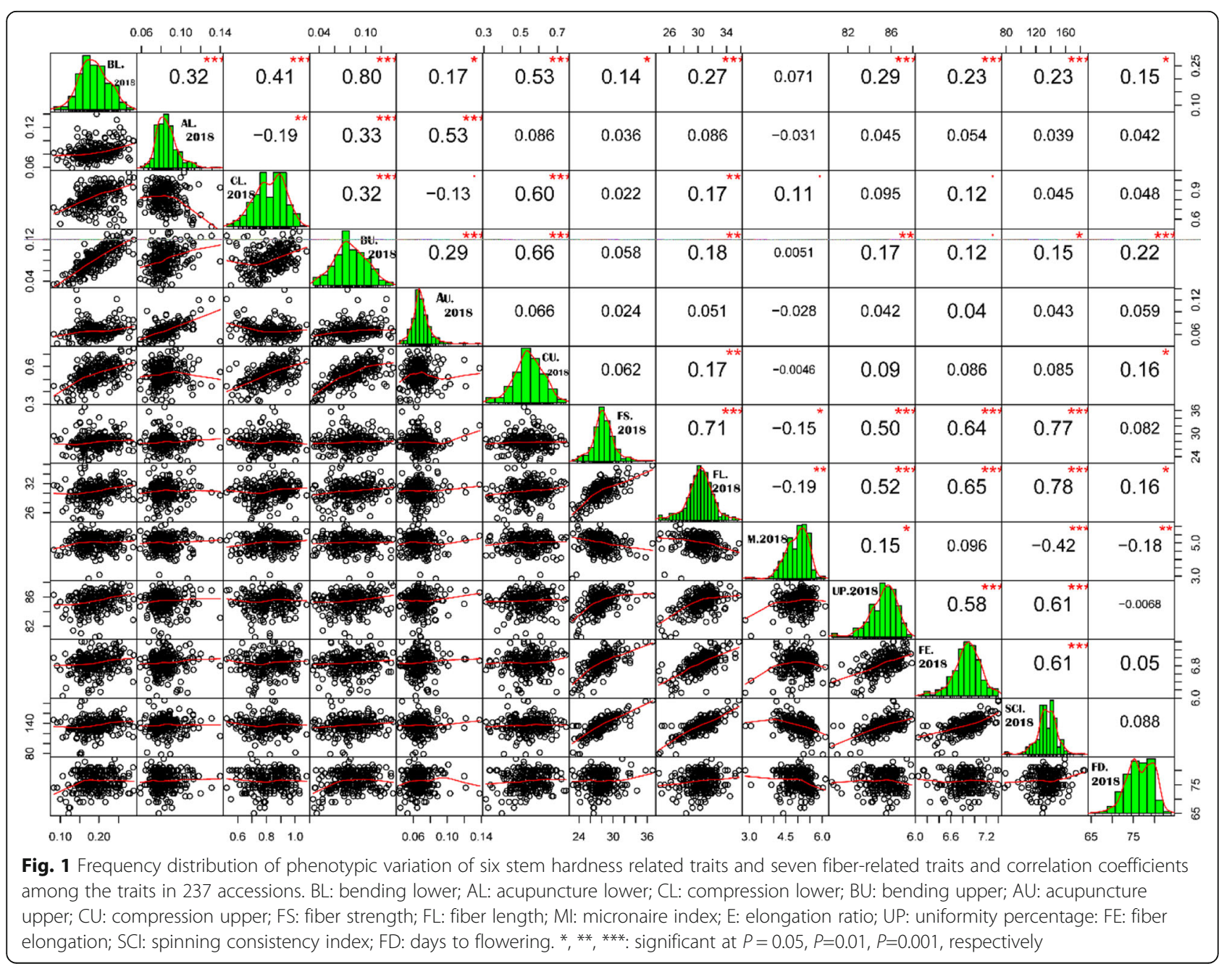




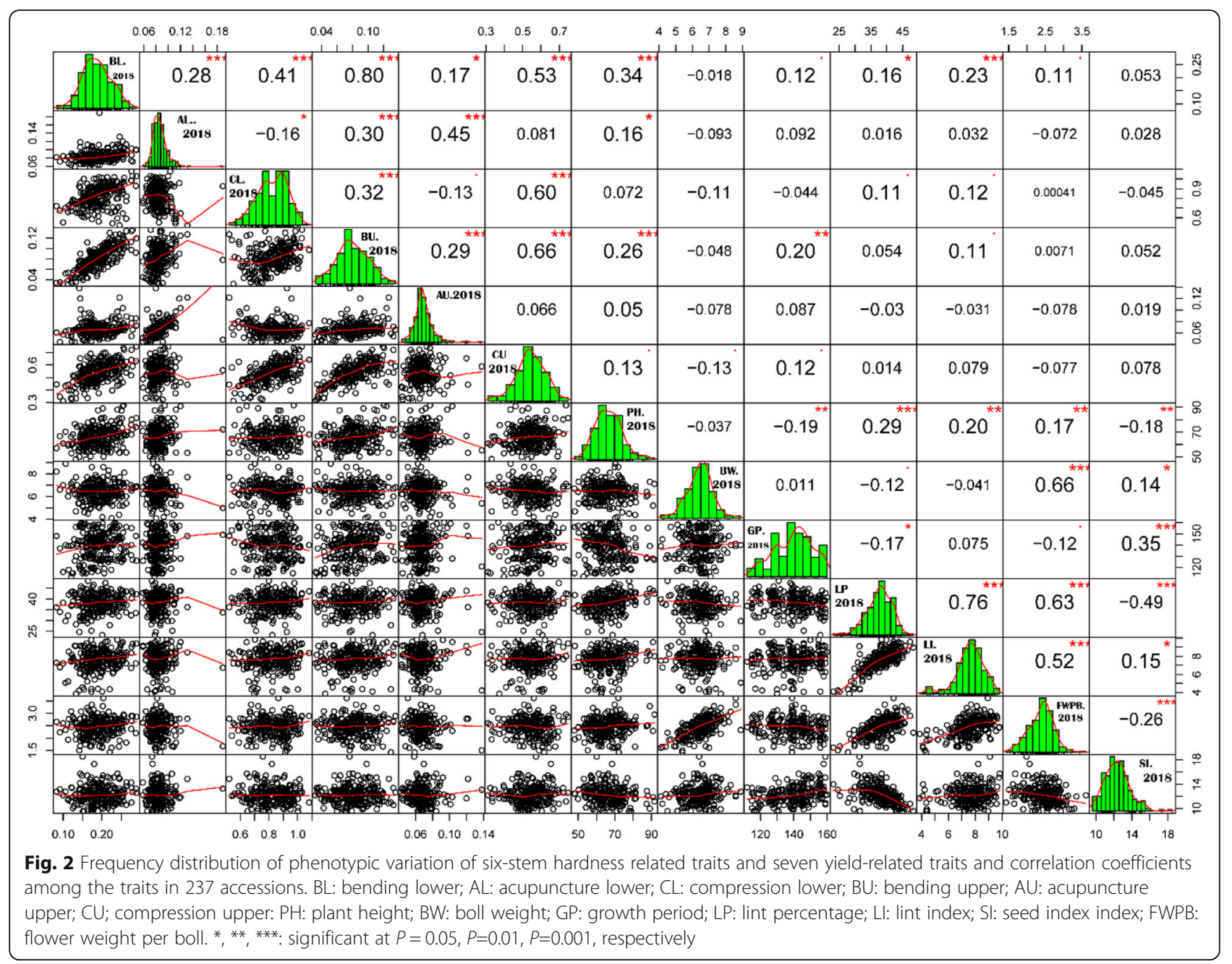

The lint index (LI) is the main feature and contributes significantly to the lint percentage increase. The promising cultivars showed a maximum lint percentage due to the close association of the lint index (LI) with the lint percentage. Our current findings have demonstrated an important correlation between the LI \& growth period (GP) with the bending (BL and $\mathrm{BU}$ ) and compression ( $\mathrm{CL}$ and $\mathrm{CU}$ ). Bending lower (BL) was positively associated with lint yield features such as LI and GOT\%. The GOT\% has a positive and substantial correlation with the lint index, according to (Hussain et al. 2010). Positive observations were found by Scholl and Miller (1976), while Tyagi (1994) stated that the GOT\% was negatively associated with the lint index. Positive associations between lint index and lint percentage suggest an increased cottonseed yield. So our result also indicates that the lint index and the lint percentage are significant elements for enhancing cotton yield and should be considered during the breeding program.
Plant height $(\mathrm{PH})$ is one of the major morphological features, which plays a key part and is closely associated with plant bolls (if there is no lodging) with the ultimate positive impact on cotton yield. Considering the lodging risk and mechanical picking, cotton breeders are mostly interested in short-stature plants, but the plant height is strongly associated with bolls per plant and seed yields (Khan 2003). The present correlation results showed that bending, acupuncture \& compression have a positive correlation with $\mathrm{PH}$. The stability and adaptability of G. hirsutum cultivars were studied by Meena et al. (2007) and reported varied values for yield components and plant height. The varieties of upland cotton were also evaluated by Suinaga et al. (2006) and it was found that the plant height was associated positively with the seed cotton yield and bolls per plant. The positive correlation between plant height and seed cotton yield was observed by Khan (2003), Soomro et al. (2005), and Zhou and Zhang (2006), and their research showed that plant height contributed $70 \%$ of the total variability in 
seed cotton yield. Therefore, it is concluded that in cotton crops, reasonable height of the plant is desirable if no lodging occurred.

Obtaining high seed yield per unit is one of the most important challenges in G. hirsutum breeding. Several agronomic traits are important for improving yield traits. Boll weight is the second major yield component and has a greater contribution to the enhancement of seed cotton yield. A similar proportion and variation for boll weight concerning the cottonseed yield was observed by Khan (2003) and Copur (2006). For yields and other economic characters, Zhou and Zhang (2006) and Meena et al. (2007) assessed various G. hirsutum varieties, significant variations were observed for boll weight and the effect on cottonseed yield was positive. The correlation results showed that bending lower (BL) and compression upper (CU) have a positive correlation with BW, GP, and FEPB. Batool et al. (2010) and Makhdoom et al. (2010) also stated that boll weight was positive for yield and it had a higher contribution to the yield improvement for upland cotton. Results also revealed that the boll weight following the bolls per plant had a positive effect on seed cotton yield. Therefore, it is concluded that boll weight is an important yield component and should be kept in mind while breeding for seed cotton yield.

Numerous characteristics affect the final yield of cotton as well as quality attributes. This study measured stem hardness and agronomic characters of a diverse set of cotton accessions to assess their variability and interrelationships. Stem hardness may have a direct effect on yield by reducing stem lodging and an indirect effect on fibers because of possible shared pathways in strengthening cell walls.

\section{Conclusions}

An evaluation of 237 accessions of the Chinese Cotton Germplasm Collection for stem hardness and agronomic characters showed sufficient variation to enable selection to improve several of these traits for cotton improvement. The data suggests inter-relationships among several traits and may simplify the improvement of multiple traits at once. Of most interest was the data suggesting relationships between stem hardness and fiber quality traits. Selection for stem hardness may improve yield by reducing losses due to stem lodging and improve fiber characteristics because of the possible sharing of pathways in strengthening cell walls of both structures. These analyses greatly simplify the breeder's selection of germplasm from a large collection and may speed up favorable gene accumulation in breeding schemes like recurrent selection for these traits. Also, the phenotypic data for stem hardness may be used in our subsequent genome-wide association studies for G. hirsutum.

\section{Supplementary Information}

The online version contains supplementary material available at https://doi. org/10.1186/s42397-021-00082-8.

Additional file 1 : Table S1. Descriptive statistics of 20 traits in 2017 and 2018. Table S2. Stem hardness variation among Gossypium hirsutum genotypes.

Additional file 2: Figure S1a. Parts of cotton dry stem. Figure S1b. Plant stem strength meter. Figure S2: Frequency distribution of phenotypic variation of six stem hardness related traits BL: bending lower; AL: acupuncture lower; $\mathrm{CL}$ : compression lower; BU: bending upper; $\mathrm{AU}$ : acupuncture upper; $\mathrm{CU}$; compression upper: and 7 fiber-related traits and correlation coefficients among the traits in 237 accessions. FS: fiber strength; FL: fiber length; MI: micronaire; E: elongation ratio; UP: Uniformity percentage: FE: fiber elongation; SCl: spinning consistency index; FD: days to flowering. ${ }^{*},{ }^{* *},{ }^{* * *}$ :significant at $P=0.05, P=0.01, P=0.001$, respectively. Figure S3: Frequency distribution of phenotypic variation of six-stem hardness related traits BL: bending lower; $A L$ : acupuncture lower; $\mathrm{CL}$ : compression lower; BU: bending upper; $\mathrm{AU}$ : acupuncture upper; $\mathrm{CU}$; compression upper: and seven yield-related traits and correlation coefficients among the traits in 237 accessions. PH: plant height; BW: boll weight; GP: growth period; LP: lint percentage; LI: lint index; SI: seed index; FWPB: flower weight per boll. ${ }^{*},{ }^{* *},{ }^{* *}$ : significant at $P=0.05, P=$ $0.01, P=0.001$, respectively.

\section{Acknowledgments}

Not applicable.

\section{Authors' contributions}

Raza I, Du XM designed the study. Raza I, Hu DW, Li HG, He SP, Nazir MF, Yasir M, lqbal MS, Wang XY, Jia YH, Pan ZE, Geng XL, Wang LR and Pang BY performed the experiment and collected data. Raza I and Ahmad A analyzed the data. Raza I wrote the manuscript. Du XM, Ahmad A, Hu DW review the manuscript. Supervision: Du XM. All authors read and approved the final version of manuscript.

\section{Funding}

This work was supported by funding from National Key Technology R\&D Program, Ministry of Science and Technology (2016YFD0100306,

2016YFD0100203), National Natural Science Foundation of China (grants 31671746).

Availability of data and materials

No other data related to this study is available at this time.

\section{Declarations}

Ethics approval and consent to participate Not applicable.

\section{Consent for publication}

Not applicable.

\section{Competing interests}

The authors declare that they have no competing interests.

Received: 16 June 2020 Accepted: 23 February 2021

Published online: 28 March 2021

\section{References}

Al-Ghazi Y, Bourot S, Arioli T, et al. Transcript profiling during fiber development identifies pathways in secondary metabolism and cell wall structure that may contribute to cotton fiber quality. Plant Cell Physiol. 2009;50:1364-81 https:// doi.org/10.1093/pcp/pcp084.

Amthor JS. From sunlight to phytomass: on the potential efficiency of converting solar radiation to phyto-energy. New Phytol. 2010;188:939-59 https://doi. org/10.1111/j.1469-8137.2010.03505.x.

Astel A, Astel K, Biziuk M. PCA and multidimensional visualization techniques united to aid in the bioindication of elements from transplanted Sphagnum 
palustre moss exposed in the Gdańsk City Area. Environ Sci Pollut Res Int. 2008;15:41 https://doi.org/10.1065/espr2007.05.422.

Batool S, Khan NU, Makhdoom K, et al. Heritability and genetic potential of upland cotton genotypes for morpho-yield traits. Pak J Bot. 2010;42(2):1057-64.

Beeck CP, Wroth J, Cowling WA. Genetic variation in stem strength in field pea (Pisum sativum L.) and its association with compressed stem thickness. Aust J Agric Res. 2006;57:193-9 https://doi.org/10.1071/AR05210.

Cai T, Peng D, Wang R, et al. Can intercropping or mixed cropping of two genotypes enhance wheat-lodging resistance? Field Crop Res. 2019;239:10-8 https://doi.org/10.1016/j.fcr.2019.05.009.

Cartea ME, Picoagea A, Soengas P, Ordás A. Morphological characterization of kale populations from northwestern Spain. Euphytica. 2002;129:25-32.

Chen B, Xu K, Li J, et al. Evaluation of yield and agronomic traits and their genetic variation in 488 global collections of Brassica napus L. Genet Resour Crop Evol. 2014;61:979-99 https://doi.org/10.1007/s10722-014-0091-8.

Chen ZI, Scheffler BE, Dennis E, et al. Toward sequencing cotton (Gossypium) genomes. Plant Physiol. 2007;145:1303-10 https://doi.org/10.1104/pp.107.107672.

Copur O. Determination of yield and yield components of some cotton cultivars in semi-arid conditions. Pak J Biol Sci. 2006;9(14):2572-8.

Dai PH, Sun JL, Jia YH, Du XM, Wang M. Construction of core collection of upland cotton based on phenotypic data. J Plant Genet Resour. 2016;17:9618 (in Chinese with English abstract).

Fang C, Ma Y, Wu S, et al. Genome-wide association studies dissect the genetic networks underlying agronomical traits in soybean. Genome Biol. 2017a;18: 161 https://doi.org/10.1186/s13059-017-1289-9.

Fang L, Wang Q, Hu Y, et al. Genomic analyses in cotton identify signatures of selection and loci associated with fiber quality and yield traits. Nat Genet. 2017b;49:1089-98 https://doi.org/10.1038/ng.3887.

Granati E, Bisignano V, Chiaretti D, et al. Characterization of Italian and exotic Lathyrus germplasm for quality traits. Genet Resour Crop Evol. 2013;50:27380 https://doi.org/10.1023/A:1023562532753.

Hirano K, Okuno A, Hobo T, et al. Utilization of stiff culm trait of rice smos 1 mutant for increased lodging resistance. PLoS One. 2014;9:e96009 https://doi. org/10.1371/journal.pone.0096009.

Huang $\mathrm{C}$, Nie XH, Shen $\mathrm{C}$, et al. Population structure and genetic basis of the agronomic traits of upland cotton in China revealed by a genome-wide association study using high-density SNPs. Plant Biotechnol J. 2017;15:137486 https://doi.org/10.1111/pbi.12722.

Huang JF, Chen F, Wu SY, et al. Cotton GhMYB7 is predominantly expressed in developing fibers and regulates secondary cell wall biosynthesis in transgenic Arabidopsis. Sci China Life Sci. 2016;59:194-205 https://doi.org/10.1 007/s11427-015-4991-4.

Hussain K, Khan IA, Sadaqat HA, Amjad M. Genotypic and phenotypic correlation analysis of yield and fiber quality determining traits in upland cotton (Gossypim hirsutum). Int J Agric Biol. 2010;12:348-52.

Ishimaru K, Togawa E, Ookawa T, et al. New target for rice lodging resistance and its effect in a typhoon. Plant. 2008;227:601-9.

Kaiser HF. The application of electronic computers to factor analysis. Educ Psychol Meas. 1960;20:141-51. https://doi.org/10.1177/001316446002000116.

Kamara AY, Kling JG, Menkir A, Ibikunle O. Agronomic performance of maize (Zea mays L.) breeding lines derived from low nitrogen maize population. J Agric Sci. 2003;141:221-30 https://doi.org/10.1017/S0021859603003514.

Khan NU. Genetic analysis, combining ability and heterotic studies for yield, its components, fiber and oil quality traits in upland cotton (G. hirsutum L.). Ph. D. Dissert. Tandojam, Pakistan: Sindh Agric Univ; 2003.

Killi F, Efe L, Mustafayev S. Genetic and environmental variability in yield, yield components and lint quality traits of cotton. Int J Agric Biol. 2005;7:1007-10.

Li K, Wang H, Hu X, et al. Genome-wide association study reveals the genetic basis of stalk cell wall components in maize. PLoS One. 2016;11:e0158906 https://doi.org/10.1371/journal.pone.0158906.

Ma Z, He S, Wang X, et al. Resequencing a core collection of upland cotton identifies genomic variation and loci influencing fiber quality and yield. Nat Genet. 2018;50:803-13 https://doi.org/10.1038/s41588-018-0119-7.

Makhdoom K, Khan NU, Batool S, et al. Genetic aptitude and correlation studies in G. hirsutum L. Pak J Bot. 2010;42(3):2011-7.

Meena RA, Monga D, Kumar R. Undescriptive cotton cultivars of north zone: an evaluation. J Cotton Res. 2007;21(1):21-3.

Meinert MC, Delmer DP. Changes in biochemical composition of the cell wall of the cotton fiber during development. Plant Physiol. 1977;59:1088-97.

Mohsenin NN. Physical properties of plant and animal materials. 2. New York: Gordon and Breach Science Publishers Inc.; 1986. p. 58-76.
Peddersen JF, Toy JJ. Measurement of sorghum stalk strength using the missourie - modified electronic rent penetrometer. Mydica. 1999;44:155-8.

Peng DL, Chen XG, Yin YP, et al. Lodging resistance of winter wheat (Triticum aestivum L.): lignin accumulation and its related enzymes activities due to the application of paclobutrazol or gibberellin acid. Field Crop Res. 2014;157: 1-7 https://doi.org/10.1016/j.fcr.2013.11.015.

Persson S. Mechanics of cutting plant material. St. Joseph: American Society of Agricultural Engineers; 1987.

Pettigrew WT. Environmental effects on cotton fiber carbohydrate concentration and quality. Crop Sci. 2001;41:1108-13.

Pettigrew WT. The effect of higher temperatures on cotton lint yield production and fiber quality. Crop Sci. 2008;48:278-85.

Salihu S, Grausgruber H, Ruckenbauer P. Agronomic and quality performance of international winter wheat genotypes grown in Kosovo. Cereal Res Commun. 2006:34:957-64.

Scholl RL, Miller PA. Genetic associations between yield and fiber strength in upland cotton. Crop Sci. 1976;16:780-3.

Soomro AR, Kakar RG, Ali H, Abid SA. Comparison of yield and its components in some commercial cotton varieties. Indus J Plant Sci. 2005;4(4):545-52.

Suinaga FA, Bastos CS, Rangel LEP. Phenotypic adaptability and stability of cotton cultivars in Mato Grosso state, Brazil. Pesquisa Agropecuaria Trop. 2006;36(3): 145-50.

Sun Z, Wang X, Liu Z, et al. Genome-wide association study discovered genetic variation and candidate genes of fibre quality traits in Gossypium hirsutum L. Plant Biotechnol J. 2017;15:982-96 https://doi.org/10.1111/pbi.12693.

Tahri M, Benyaich F, Bounakhla M, et al. Multivariate analysis of heavy metal contents in soils, sediments and water in the region of Meknes (Central Morocco). Environ Monit Assess. 2005;102:405-17.

Tanaka K, Murata K, Yamazaki M, et al. Three distinct rice cellulose synthase catalytic subunit genes required for cellulose synthesis in the secondary wall. Plant Physiol. 2003;133:73-83.

Tang JH, Teng WT, Yan JB, et al. Genetic dissection of plant height by molecular markers using a population of recombinant inbred lines in maize. Euphytica. 2007;155:117-24 https://doi.org/10.1007/s10681-006-9312-3.

Timpa JD, Ramey HH. Relationship between cotton fiber strength and cellulose molecular-weight distribution - HV calibration standards. Text Res J. 1994;64:557-62.

Tokalıoglu S, Kartal S. Multivariate analysis of the data and speciation of heavy metals in street dust samples from the organized industrial district in Kayseri (Turkey). Atmos Environ. 2006:40:2797-805.

Tyagi AP. Correlation coefficient and selection indices in upland cotton (Gossypium hirsutum L.). Indian J Agric Res. 1994;28:189-96.

Ververis C, Georghiou K, Christodoulakis N, et al. Fiber dimensions, lignin and cellulose content of various plant materials and their suitability for paper production. Ind Crop Prod. 2003;19:245-54.

Wang H, Guo Y, LV F, et al. The essential role of GhPEL gene, encoding a pectate lyase, in cell wall loosening by depolymerization of the de-esterified pectin during fiber elongation in cotton. Plant Mol Biol. 2010;72:397-406 https://doi. org/10.1007/s11103-009-9578-7.

Wang MJ, Tu LL, Lin M, et al. Asymmetric subgenome selection and cisregulatory divergence during cotton domestication. Nat Genet. 2017;49:579_ 87 https://doi.org/10.1038/ng.3807.

Wendel JF. New World tetraploid cottons contain Old World cytoplasm. Proc Natl Acad Sci U S A. 1989;86:4132-6.

Yongming $H$, Peixuan D, Junji C, Posmentier ES. Multivariate analysis of heavy metal contamination in urban dusts of Xi'an, Central China. Sci Total Environ. 2006;355:176-86 https://doi.org/10.1016/j.scitotenv.2005.02.026.

Žáková M, Benková M. Characterization of spring barley accessions based on multivariate analysis. Commun Biom Crop Sci. 2006;1:124-34.

Zhang JF, Fang H, Zhou HP, et al. Genetics, breeding, and marker-assisted selection for Verticillium wilt resistance in cotton. Crop Sci. 2014;54:1289-303.

Zhou TH, Zhang HP. Comparative study on yield and main agri-characters of five hybrids coloured cotton varieties. J. Anhui Agric. Univ. 2006;33(4):533-6. 